\title{
The use of cytogenetic tools for studies in the crop-to-wild gene transfer scenario
}

\author{
E. Benavente M. Cifuentes J.C. Dusautoir J. David
}

Departamento de Biotecnología, ETS Ingenieros Agrónomos, Universidad Politécnica de Madrid, Madrid (Spain) Unité Mixte de Recherche Diversité et Adaptation des Plantes Cultivées (UMR-DIAPC),

Supagro Montpellier-INRA-IRD, Montpellier (France)

\begin{abstract}
Interspecific hybridization in plants is an important evolutionary phenomenon involved in the dynamics of speciation that receives increasing interest in the context of possible gene escapes from tran sgenic crop varieties. Crops are able to cross-pollinate with a number of wild related species and exchange chromosome segments through homoeologous recombination. In this paper, we review a set of cytogenetic techniques that are appropriate to document the different steps required for the stable introgression of a chromosome segment from a donor species (i.e., the crop)
\end{abstract}

into a recipient species (i.e., the wild). Several examples in hybrids and derivatives are given to illustrate how these approaches may be used to evaluate the potential for gene transfer between crops and wild relatives. Different techniques, from classical chromosome staining methods to recent developments in molecular cytogenetics, can be used to differentiate genomes and identify the chromosome regions eventually involved in genetic exchanges. Some clues are also given for the study of fertility restoration in the interspecific hybrid forms.
Observation of interspecific hybrids between different taxa in nature is rare but recurrent (Ellstrand et al., 1996; Arnold, 1997). Most often, such hybrids are almost fully sterile and therefore were long considered as dead end forms. Nowadays, the new technological tools permit us to investigate whether a majority of plant species may be derived from past hybridization events (e.g., Stebbins, 1958) and this is acknowledged to be an important phenomenon in angiosperm evolution (Rieseberg and Ellstrand, 1993; Rieseberg and Wendel, 2004). The reality of ancient introgression is difficult to establish but phylogenetic studies are increasingly providing indirect evidence. Interspecific gene transfers cancel the accumulated nucleotide divergences between species. Then the phylogenetic trees obtained for a gene that was kept isolated within each species and for a gene exchanged after their evolutionary differentiation can be inconsistent. These phylogenetic incongruities support a reticulate evolution pattern (Vriesendorp and Bakker, 2005; Marhold and Lihova, 2006).

Following hybridization, gene flow may result in the introgression of chromosome segments from one species to another by direct and recurrent back crosses. Alternatively, interspecific hybrids might give birth to new fertile species either via spontaneous and instantaneous chromosome doubling (allopolyploidy; e.g., wheat and oilseed rape) or via the fixation of viable recombinant chromosome sets (homoploidy; see Rieseberg, 1997; Rieseberg and Carney, 1998). These stable and fertile allopolyploid and homoploid forms can also constitute bridges and gene reservoirs for subsequent gene flows back to their diploid progenitors.

Introgression can then act on ecosystems by species invasion or replacement (Ellstrand, 2003) and may thus have an impact in biological diversity. In the crop-wild context, with or without genetically transformed varieties, evolution towards nasty weeds is also a major rising concern (Ellstrand et al., 1999; Burke et al., 2002; Lu and Snow, 2005). Weeds incorporating transgenes carrying insect or disease 
resistance, or resistance to environmental stresses, are likely to display increased overall fitness and competitiveness, and their spread may have serious agronomic and environmental implications (Warwick et al., 2003; Watrud et al., 2004; Reichman et al., 2006). Natural selection of a favourable allele in an interspecific context has long been neglected but while the spread of an introgressed allele is possible through neutral evolution, it can thrive much more successfully through natural selection even with low selective advantage (Arnold et al., 1999; Rieseberg and Burke, 2001).

Wild species and crops are growing in sympatry in many documented situations (see Ellstrand et al., 1999 for a review). In these complexes of species, either the direct wild ancestor of the crop or any related species could be a possible recipient of the crop genes. The probability of interspecific hybridization depends on various factors, such as phylogenetic relatedness, mating systems, and density and spatial distribution of wild relatives (Warwick et al., 2003; Chevre et al., 2003). Nevertheless, the main goal is not to prove that interspecific hybridization occurs in nature and may impact the species communities, but to document the likelihood of chromosome segment transmission and to describe the ways of gene exchange and transfer between species.

Figure 1 illustrates the various pathways that a crop nucleotide sequence must follow to be stably incorporated into a wild related species. In this paper we review the utility of cytological methodologies to investigate the critical steps in the route and to identify the mechanisms and the fate of a transferred chromosome segment.

\section{The tools}

This section briefly describes the most common methods used for chromosome analysis in interspecific hybrids and their progenies.

\section{Classical cytogenetic methods}

Traditional dyes (aceto-carmine, aceto-orcein, Feulgen and variants) bind chromatin and nicely stain chromosomes for optical microscopy. Despite the great development of newer alternatives, these staining methods are still commonly used to visualize chromosomes both in mitotic and meiotic cells. Their main limitation is that individual chromosomes within a complement cannot be identified unless they differ morphologically, i.e., by size, centromere position, presence or location of secondary constrictions, etc.

Several staining methods provide distinctive and reproducible banding patterns for specific chromosomes or genomes based on the size and location of different classes of chromatin. Among the classical banding methods, C-banding has been the most frequently used for identification of individual plant chromosomes either at mitosis or meiosis (e.g., Dhaliwal et al., 1977; Gill et al., 1991) (Fig. 2). It is worth mentioning that a perfectly distinctive band pattern on mitotic karyotypes may not be as easily resolved on meta-

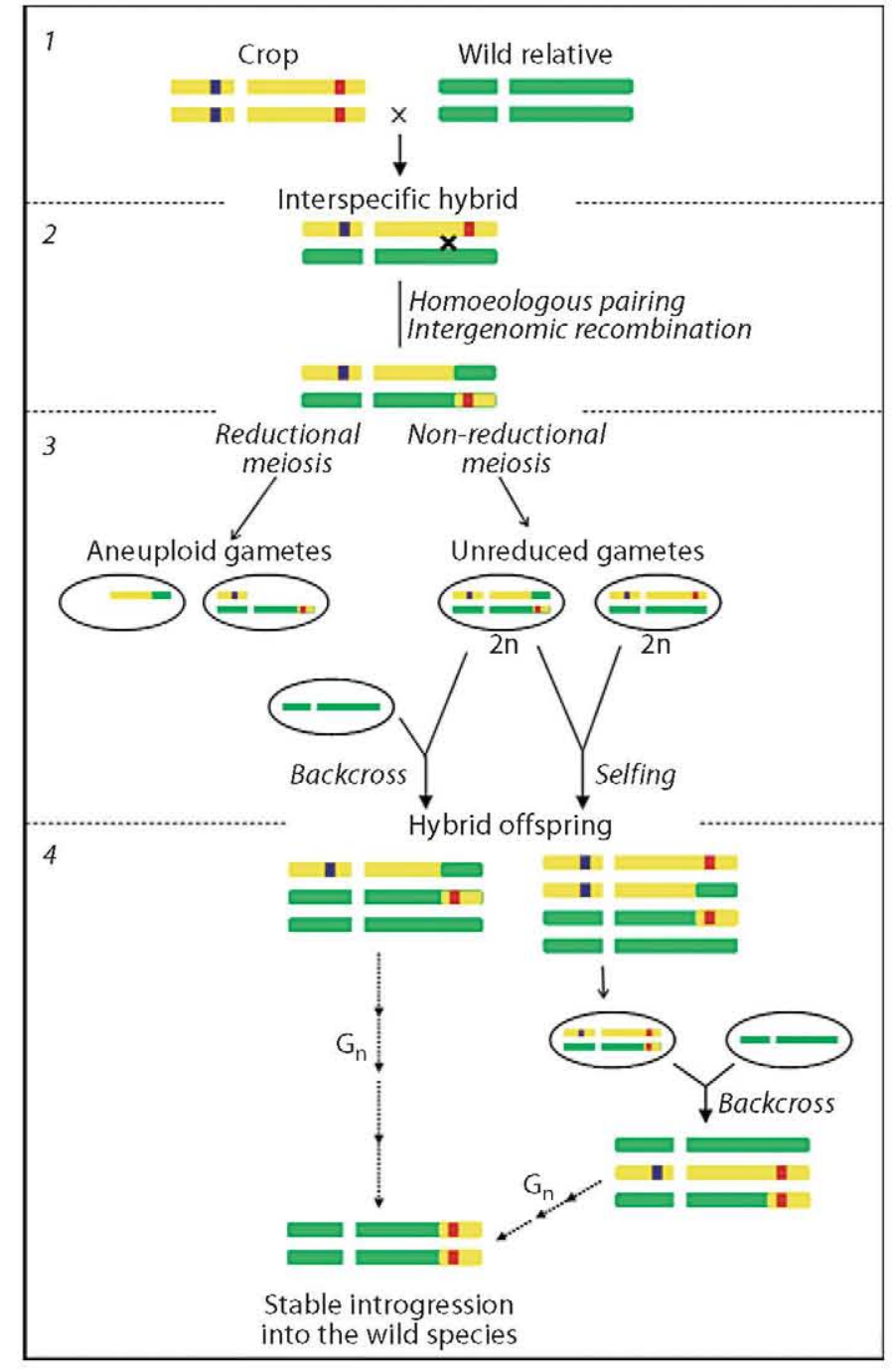

Fig. 1. Steps in the crop-to-wild gene flow route. 1: Interspecific hybridization. 2: Chromatid exchange between crop and wild chromosomes. 3: Production of functional gametes and fertilization. 4: Transmission of crop-wild recombinant chromosomes during karyotype evolution. The red block represents a crop genetic sequence successfully introg ressed, whereas the blue block represents a non-recombined sequence that will likely be lost during karyotype evolution in the hybrid lineage.

phase-I (MI) cells due to the different morphology of chromosomes at this meiotic stage. This explains why many reports that document the employment of $\mathrm{C}$-banding for meiotic MI pairing analyses have not used the technique to identify specific chromosomes but to simply discriminate genomes with sharply distinct banding patterns (e.g., Hutchinson et al., 1983).

\section{Cytomolecular methods}

Fluorescent in situ hybridization (FISH), using different classes of DNA sequences as probes, has been extensively used for cytological discrimination of specific chromosomes and individual genomes in many plant species (Jiang and Gill, 1994, 2006). The following sections will provide 
numerous references illustrating the use of different FISH approaches in interspecific hybrids and derivatives from most of the crops for which gene flow to wild relatives has been documented (wheat, rice, oilseed rape, cotton or sunflower, among others).

FISH using total genomic DNA labelled probes (GISH) easily and reliably informs on the genome adscription of specific chromosomes (or chromosomal segments) in many multigenomic materials based on colour codes (Figs. 3-5). The technique is sometimes referred to as multicolor-GISH when differentially labelled genome probes are simultaneously hybridized to chromosome spreads. In some instances, the presence of shared sequences in the target and non target genomes results in cross-hybridization signals of total genomic DNA probes which could hinder their undoubted discrimination. Other classes of genome-specific DNA probes offer an emerging alternative to solve this technical problem. So, BAC derived probes are now available for FISH approaches (BAC-FISH) to paint constituent genomes in some important allopolyploid crops like wheat (Zhang et al., 2004) and oilseed rape (Leflon et al., 2006) (Fig. 6). Another promising result is the successful discrimination of parental genomes in interspecific hybrids within the genus Oryza by means of Cot-1 DNA fluorescent probes (Lan et al., 2006) (Fig. 7). It must be noticed that the labelling pattern of some genome-specific repeated DNA probes is spotty or banding-like, instead of homogeneous along the entire chromosomes. This may represent a limitation for visualization of introgressions involving non-labelled chromosome segments.

Many other different DNA probes have been successfully used for identification of specific chromosomes based on physical location of FISH signals. The whole chromosome complement of some crop species can be individualized by sequential FISH using appropriate sets of selected repeated DNA probes (Cuadrado et al., 1997; Irigoyen et al., 2002). However, only a few chromosomes are marked in most instances (e.g., Pickering et al., 2004). Combination of repeated and genomic probes has been demonstrated to be a great improvement in identification of particular chromosomes and chromosomal segments in multigenomic materials (Dong etal., 2001; Maluszynska and Hasterok, 2005; Cifuentes et al., 2006; Herrera et al., 2007) (Figs. 8-10).

It is far from the scope of this section to describe in any detail the different types of DNA probes (from repeated DNA sequences and BAC clones to microdissected chromosomes or single-copy genes) and chromatin targets (mitotic chromosomes, pachytene spreads, extended DNA fibers, etc.) that can be used in FISH experiments (reviewed in Jiang and Gill, 1994, 2006; Lam et al., 2004). However, based on the current technological progress, the potential of FISH approaches for identification of specific segments on individual chromosomes seems unlimited. A recent nice example is the development of a complete set of chromosomespecific BAC-derived probes that allows unambiguous identification of all the chromosome pairs in tetraploid cotton (Wang et al., 2007).

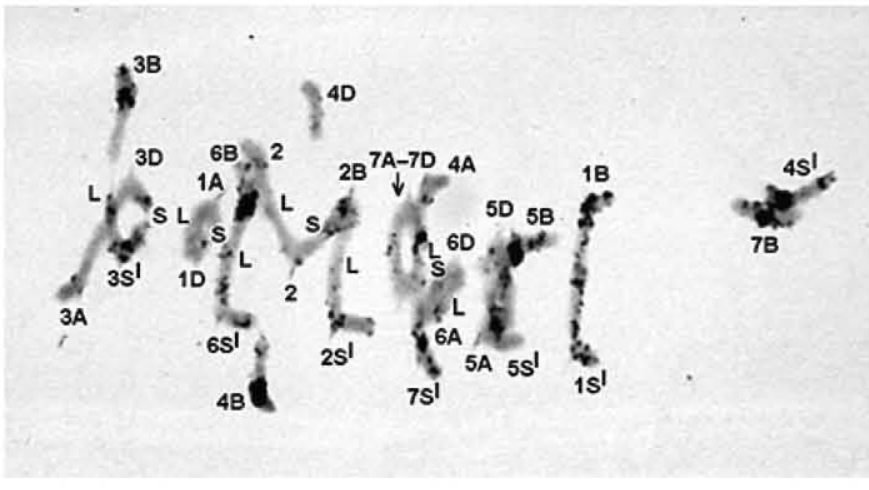

Fig. 2. C-banding in MI meiotic chromosomes of a bread wheat $x$ Ae. longissima hybrid $\left(2 \mathrm{n}=28\right.$; $\left.\mathrm{ABDS}^{\mathrm{l}}\right)$. All chromosomes, except $2 \mathrm{~A}$ and $2 \mathrm{D}$, are individually identified on the basis of their C-banding pattern. Kindly provided by Dr. T. Naranjo.

Figs. 3-10. FISH methodologies for genome painting (3-8) and identification of specific chromosomes $(8-10)$ in interspecific hybrids and derivatives. For protocol details, see the original papers. Reproduced with kind permission of NRC Research Press (3,9 and 10) or Springer Science and Business Media (4-8). 3. GISH on a mitotic spread of an interspecific hybrid between sugarcane (Saccharum officinarum) (green fluorescence) and its wild relative Erianthus arundinaceus (red fluorescence). From Piperidis et al. (2000). 4. GISH on a meiotic MI cell of an $\mathrm{F}_{1}$ hybrid between tomato (Lycopersicon esculentum) (pink) and Solanum lycopersicoides (blue, after DAPI staining) showing extensive homoeologous chromosome pairing. From Ji and Chetelat (2003). 5. GISH on meiotic post-MI chromosomes of an $\mathrm{F}_{1}$ hybrid between Oriental $\times$ Asiatic lilies. Arrows and arrowheads point to recombinant chromosomes. Oriental and Asiatic genomes are colored pink-red and blue, respectively. Bar: $10 \mu \mathrm{m}$. From Barba-Gonzalez et al. (2005). 6. MI cell from a triploid hybrid $(2 \mathrm{n}=29, \mathrm{AAC})$ between Brassica rapa $(2 \mathrm{n}=20, \mathrm{AA})$ and B. napus $(2 \mathrm{n}=38, \mathrm{AACC})$ after FISH with two BACderived probes. One of them hybridizes to the $C$ genome (green) and the other labels three A genome chromosomes (pink). From Leflon et al. (2006). 7. Mitotic spread of an Oryza sativa $(2 \mathrm{n}=24$, AA $) \times 0$. officinalis $(2 \mathrm{n}=24, \mathrm{CC}) \mathrm{F}_{1}$ interspecific hybrid $(2 \mathrm{n}=24, \mathrm{AC})$ after FISH with a labelled probe of Cot-1 DNA from O. officinalis. After combination of images from DAPI staining (a) and probe hybridization (b), the labelled genome is painted pink (c). Bars: $5 \mu \mathrm{m}$. From Lan et al. (2006). 8. Meiotic MI of a durum wheat $(2 \mathrm{n}=28, \mathrm{AABB}) \times$ Aegilops geniculata $\left(2 \mathrm{n}=28, \mathrm{U}^{\mathrm{g}} \mathrm{Ug}^{\mathrm{g}} \mathrm{M}^{\mathrm{g}} \mathrm{M}^{\mathrm{g}}\right) \mathrm{F} 1$ hybrid $\left(2 \mathrm{n}=28, \mathrm{ABUg}^{\mathrm{g}} \mathrm{M}^{\mathrm{g}}\right)$ with discrimination of the pairing pattern between A (green), B (red) and Ae. geniculata (brown) genomes. Combination of genomic probes with the ribosomal DNA probe pTa71 (pale yellow signals) allows identification of main NOR-bearing chromosomes. From Cifuentes et al. (2006). 9. Mitotic spread of a breeding line of coffee (Coffea arabica) carrying introgression from its wild relative C. liberica. Combination of a C. $l i$ berica genomic probe (pink) and a chromosome-specific $\mathrm{BAC}$ probe (green) provides physical localization of introgressed chromatin on chromosome pair 1 of coffee (arrowed and magnified). Bar: $5 \mu \mathrm{m}$. From Herrera et al. (2007). 10. Sequential GISH and FISH images of a mitotic cell from a potato breeding line with introgression from the wild species Solanum brevidens. Identification of the three potato chromosomes carrying alien chromatin (arrows) is based on co-localization of the $S$. brevidens genomic probe signals (a) with either the ribosomal DNA probe pTa71 (b) or any of two potato chromosome-specific BAC-derived probes (c, d). Arrowheads point to FISH signals on other potato chromosomes. Bar: $10 \mu \mathrm{m}$. From Dong et al. (2001). 

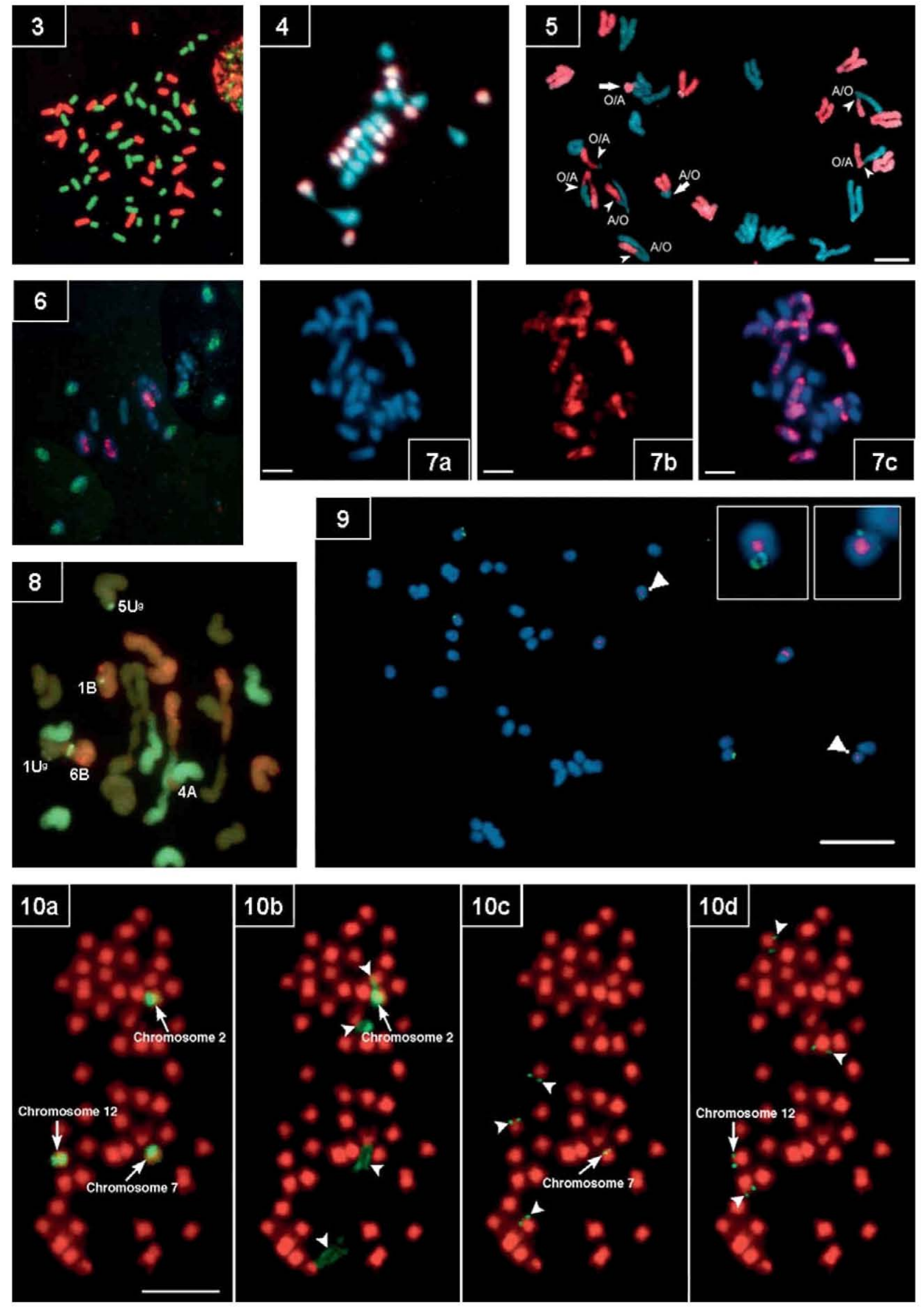
DAPI is a fluorescent dye that binds DNA and stains chromosomes for fluorescent microscope observations. In some species, this staining technique represents a helpful tool for the identification of individual chromosomes (e.g., Fransz et al., 1998). However, DAPI is generally used as the modern equivalent of traditional dyes, for mere visualization of chromosomal bodies without any further detail.

\section{Flow cytometry}

Flow cytometry can be used to measure the amount of DNA per cell, for chromosome counting and determination of cell size (e.g., Dolezel et al., 1994; Bretagnolle and Thompson, 1995). Its applications to the study of the processes described below will be considered.

\section{Studies on the gene flow route}

The majority of the studies presented here was conducted on artificial hybrid combinations mostly obtained for breeding purposes, but demonstrate that the analytical tools are valuable in the scope of crop-to-wild spontaneous gene flows.

\section{Hybridity}

In the case that a rare individual is found within a wild population that grows in the vicinity of a crop field, both belonging to distinct but related species, several cytological analyses can confirm whether or not that out-of-type form is actually a hybrid.

When parental species differ in their DNA content, flow cytometry is a quick and precise method which represents an advantageous alternative over any approach based on chromosome analysis to check a large number of putative hybrids (e.g., Ochatt et al., 2004; reviewed in Eeckhaut et al., 2005; Marasek et al., 2006).

Karyotyping is more laborious but also more confident in any situation. Nonetheless, the technique to be employed will depend on some distinctive karyotype characteristics between the supposed parents. Thus, chromosome counting by any conventional staining method is the easiest cytogenetic tool if the parental species possesses different $2 \mathrm{n}$ values (for instance, diploid versus polyploid, or two diploids with different basic numbers) or show remarkably distinct chromosome morphologies (Eber et al., 1994; Mariam et al., 1996; Chen et al., 1997; Hussain et al., 1997). However, when the karyotypes of the parental species are similar, techniques that provide cytological discrimination between both chromosome complements such as GISH (Karlov et al., 1999; Piperidis et al., 2000), FISH with appropriate labelled probes (Lan et al., 2006) and, in some cases, C-banding (Rodriguez et al., 2000) are the only reliable methods for mitotic assessments on the hybrid nature of a plant (Figs. 3, 7).

Interspecific hybrids usually display low meiotic chromosome pairing, which is mainly attributed to reduced homology between the parental genomes. This well documented feature provides then another tool for verification of hybridity based on the level of chromosome association at meiotic MI (e.g., Xu and Lu, 2004). Traditional (or DAPI) staining methods are adequate for this purpose, so more time-consuming methods are not required. Additionally, this approach permits us to determine the $2 \mathrm{n}$ value of the individual which might be sufficient to elucidate whether it is an interspecific hybrid.

It could be argued that screening for hybrids by molecular markers is much simpler and allows quicker analysis of larger samples. However, these approaches require that the marker profile is previously demonstrated to be distinct in both parental species. Many crops are very well studied at the molecular level but much less knowledge, if any, is usually available about most wild relatives. In this case, the occurrence of false positives cannot be excluded even if a given marker had been previously considered as crop-specific. This limitation is overcome by the cyto-tools described above which may represent the only available technique in some instances, while in others they could serve to contrast the validity of molecular results.

\section{Potential of crop-to-wild genetic transfer}

The most extended method to assess the likelihood of genetic exchange between any two species has been the study of chromosome association at MI in their hybrids. This approach is based upon the generalized assumption that the level of meiotic recombination between two chromosomes (either homologous or homoeologous) strictly depends on the extent of chromosome pairing and chiasma formation between them.

Most of the studies reporting chromosome pairing analyses in interspecific hybrids are based on the scoring of meiotic configurations (namely, univalents, rod and ring bivalents, trivalents, etc.) on MI cells but some reports on the extent of synapsis at the pachytene stage can also be found (Xiong et al., 2006). Traditional dyes or modern equivalents like DAPI are the easiest and less time-consuming tools for the purpose when both parental species are diploids because the chromosomes in the hybrid have only the choice of allosyndetic (crop-wild) pairing. Then the mere counting of chromosomal arm associations (one in rod bivalents, two in ring bivalents) serves to predict the extent of intergenomic recombination between the two parental genomes (Ishizaka, 1994; Haroun, 1996; Reddy et al., 2001; Xu and Lu, 2004). It must be noted here that MI pairing between nonhom(e)ologous chromosomes has been demonstrated to occur in interspecific hybrids (e.g., Dhaliwal et al., 1977), but its frequency is always considered as negligible.

The use of uniform staining techniques is questionable in crop-wild combinations where one or both of the parental species are polyploids since autosyndetic (crop-crop or wildwild) in addition to allosyndetic MI pairing can regularly form in the hybrids. This holds for some relevant crops like wheat, cotton, and oilseed rape. In such situations, the extent of allosyndetic pairing has been frequently deduced from the number of meiotic configurations larger than expected if only autosyndetic pairing had taken place (e.g., Kerlan et al., 1993; Hussain et al., 1997; Choudhary et al., 2000). However, the occurrence of chiasmate associations between the crop 
and the wild genomes in these polyploid interspecific hybrids must be assessed by approaches ensuring that both types of pairing partners are cytologically distinguished, so the extent of crop-wild MI pairing can be accurately quantified.

C-banding was the earliest alternative in order to discern specific chromosomes or genomes on MI spread cells (Dhaliwal et al., 1977). However, its use has been almost exclusively limited to wheat and other cereals possessing large chromosomes and distinctive C-banding (Fig. 2). During the 80's and 90's, Naranjo and co-workers authored thorough reports where the meiotic pairing pattern was determined for individual wheat and related homoeologous partners in several interspecific hybrid combinations (Naranjo et al., 1987; Naranjo and Maestra, 1995; Maestra and Naranjo, 1997; Rodriguez et al., 2000). In most other cases, the C-banding technique was employed to differentiate wheat and alien genomes but further discrimination of specific chromosomes was not attempted (Hutchinson et al., 1983; Cuñado et al., 1986; Jouve and Giorgi, 1986; Fernandez-Calvin and Orellana, 1992; Fernandez-Calvin et al., 1995).

Soon after GISH proved to be able to detect alien chromatin within a wheat background (Schwarzacher et al., 1992), the technique was applied to distinguish autosyndetic from allosyndetic MI pairing in durum wheat $\times$ Thinopyrum bessarabicum hybrids (King et al., 1993). Nowadays, this cytomolecular tool has become the most extended method for MI pairing analyses of interspecific hybrids not only from wheat (e.g., Benavente et al., 1998; Jauhar et al., 2004) but from many other crop species as distinct as tomato (Ji and Chetelat, 2003), onion (Stevenson et al., 1998), barley (Zhang et al., 1999), maize (Gonzalez et al., 2006), dahlia (Gatt et al., 2000), lily (Lim et al., 2001), rice (Xiong et al., 2006) and several brassicas (Wang et al., 2004; Wei et al., 2006), among others (Figs. 4, 8). Genome painting based on genome-specific repeated DNA probes has recently been presented as a reliable alternative for discrimination between homoeologous partners in MI pairing analyses (Leflon et al., 2006) (Fig. 6).

FISH with selected probes has also allowed identification of allosyndetic MI pairing for specific ch romosomes (Pickering et al., 2004). This is highlighted by the study of Cuadrado et al. (1997) who individually recognized the whole chromosome complement of wheat $\times$ rye hybrids in MI cells by combining five distinct repeated DNA probes. When multigenomic hybrids are under analysis, sequential or simultaneous hybridization of genomic probes with ribosomal DNA and other repeated DNA probes greatly helps to characterize whether specific chromosomes are or are not involved in pairing configurations (Stevenson et al., 1998; Cifuentes et al., 2006) (Fig. 8). Meiotic MI labelling of individual chromosomes by means of BAC-FISH has also been reported by Leflon et al. (2006) (Fig. 6).

The identification and quantification of crop-wild chromosome pairing is the most valuable yield from MI pairing analyses in interspecific hybrids. However, the pattern of MI meiotic configurations can also serve to disclose structural differences between the parental genomes (Rao et al., 1992; Ulloa et al., 1994).
Under the assumption that chiasma formation is followed by chromatid exchange between the hom(e)ologous pairing partners, estimation of the extent of crop-alien meiotic recombination has been attempted in a number of interspecific hybrids by cytological analyses at anaphase I (AI) and other post-MI meiotic stages (Orellana, 1985; Benavente et al., 1996; Zhang et al., 1999). However, reliable identification of AI recombinant chromosomes is always much more problematic than discrimination of the chromosome partners in an MI pairing configuration. Some methods like C-banding and FISH with genome-specific probes provide heterogeneous labelling of the target genomes since only certain regions of their chromosomes are physically marked (see Figs. 2, 6, 8). Because of the predominantly distal chiasma location in distant hybrids, these methodologies become useless for quantification of intergenomic recombinants except if all or most of the chromosomal ends of the labelled genome are actually marked. Homogeneous differential painting of the whole chromosome complements of both parents seems then a requirement to detect any eventual crop-wild chromatid exchange. GISH can achieve a clear complete discrimination in some hybrid combinations like wheat $X$ rye (King et al., 1994; Benavente et al., 1996), Hordeum vulgare $\times$ H. bulbosum (Zhang et al., 1999), Asiatic $\times$ Oriental lilies (Barba-Gonzalez et al., 2005) or Allium cepa $\times$ A. fistulosum (Stevenson et al., 1998) (Fig. 5). However, incomplete extent of chromosome painting may prevent the accurate resolution of some recombinants, as reported for Lycopersicon esculentum $\times L$. pennellii hybrids by Ali et al. (2002). Even in hybrids with excellent GISH discrimination between the parental genomes, additional difficulties must be kept in mind when cytological analyses are performed to estimate crop-wild recombination frequencies, i.e., the technical limitations to detect small sized exchanges on highly condensed chromosomes and the restrictions to resolve exchanged fragments depending on some parameters of the GISH procedure ( $\mathrm{Lu}$ kaszewski et al., 2005).

\section{Fertility of hybrids (and their progenies)}

Interspecific hybrids will act as successful bridges for gene flow between related species in nature if they are able to produce offspring, even at low frequencies. Separate estimation of male and female fertility is of great interest since hybrid descents can be formed not only on the hybrid but also on plants growing in its vicinity after pollen dispersal. It must be noted that although some of the methodologies mentioned in this section cannot be classified as cytogenetic tools, all of them deal with reproductive cells (or tissues) and use equipment and chemicals of routine use in most labs conducting cytogenetic studies. Therefore, their inclusion has been considered pertinent for a complete overview of the different approaches that could provide information on hybrid fertility.

The simplest method to evaluate male fertility is pollen staining with traditional stains like aceto-carmine and acid fuchsin (e.g., Choudhary et al., 2002; Chen et al., 2003; Matsuoka et al., 2007). This allows a rapid confirmation of pol- 

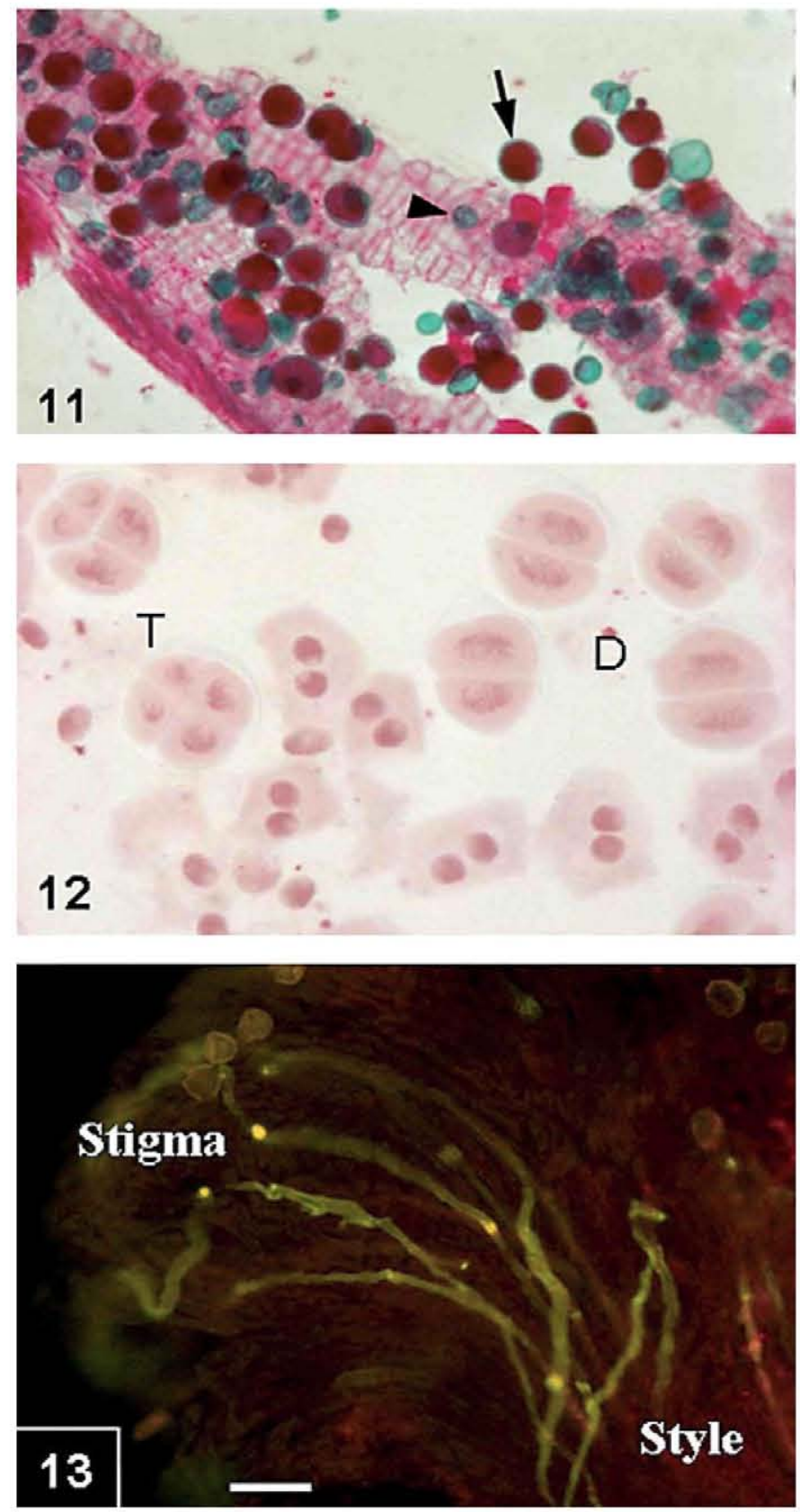

Figs. 11-13. Methodologies for male fertility studies. 11. Alexander staining of a pollen sample from a semi-fertile $\mathrm{F}_{1}$ hybrid between durum wheat and Ae. geniculata. The cytoplasm of viable pollen (arrow) stains purple while pollen walls are blue-green (arrowhead). Viable pollen grains show remarkable size variation. 12. Aceto-carmine staining of pollen mother cells at the tetrad (T) stage from a durum wheat $\times$ Ae cylindrica semi-fertile hybrid. The presence of dyads (D) evidences non-reductional meiosis and accounts for functional 2 n-pollen formation. 13. Visualization of pollen germination and penetration in the style by fluorescence microscopy after aniline blue staining of pollen tubes in cork-oak (Quercus suber). From Feijo et al. (1999). Bar: 50 $\mu \mathrm{m}$. Reproduced with kind permission of Springer Science and Business Media. len sterility, often accompanied with indehiscence of anthers in totally sterile hybrids. With Alexander stain (Alexander, 1969), the cytoplasm of viable pollen grains is stained purple while sterile grains are empty and their envelopes appear light green (Binsfeld et al., 2001; Techio et al., 2006) (Fig. 11). Fluorescein diacetate (FDA) has also been used for staining pollen samples (Ewald et al., 2000; Liu et al., 2004) with the assumption that intense fluorescence is correlated with pollen activity (Heslop-Harrison and Heslop-Harrison, 1970). Although these approaches are the most common to predict the level of male fertility, studies on pollen function in interspecific hybrids and derivatives have shown that pollen grains assumed to be viable based on their staining ability do not necessarily germinate or penetrate the female tissue (Chung et al., 1996).

Meiosis disturbances in the hybrids result in many aneuploid pollen grains (and eggs). These unbalanced gametes are usually non functional or provoke unsuccessful embryo development after self- or cross-fertilization though fertile descents can be occasionally derived. Unreduced ( $2 n$ ) gametes, which transmit the whole chromosome complement of individuals to their offspring, are mostly those involved in the fertility restoration of interspecific hybrid combinations (Bretagnolle and Thompson, 1995). Bigger pollen size is the first indicator of the production of unreduced ga metes since nuclear restitution during the first (FDR) or the second (SDR) division promotes the formation of dyads instead of the usual tetrads (see Fig. 12). Hence the volume of unreduced pollen grains will be approximately twice the usual volume of a pollen grain. In hybrids with a certain degree of fertility, it is then not infrequent to observe giant pollen grains neighbouring sterile and smaller pollen grains that correspond to the abortion of aneuploid cells (Fig. 11). Then a more accurate prediction of hybrid male fertility might be based on the frequency of large and stained (that is to say unreduced and viable) pollen grains (Stefani, 1986; Ramanna et al., 2003). The distribution of the size of heterogeneous populations of pollen can also be examined by measurements of DNA content, and estimation of unreduced male gametes based on flow cytometry analyses is documented (Van Tuyl et al., 1989). DAPI staining is also helpful to detect variation of DNA content between pollen grains (Williams et al., 1999).

The significance of unreduced gamete formation on the level of hybrid fertility has aimed at cytological studies on male gametogenesis. So counting dyads at the tetrad microspore stage (Fig. 12) has been a common alternative or complement to pollen analyses in order to assess male fertility (Nassar and Freitas, 1997; Zhang et al., 1998). However the most relevant contribution of cytogenetics on this topic has been the identification of the nuclear restitution mechanisms underlying $2 \mathrm{n}$ gamete formation in some important crops that naturally produce unreduced gametes like potato (Mok and Peloquin, 1975), alfalfa (Barcaccia et al., 2003), and blueberry (Qu and Vorsa, 1999), as well as in a number of interspecific hybrids (Lim et al., 2001, 2004; Barba-Gonzalez et al., 2005). The implication of some spindle anomalies on $2 \mathrm{n}$ pollen production by direct visualization of mi- 
crotubules and other cytoskeleton components is also documented (Genualdo et al., 1998; Conicella et al., 2003). A thorough description of cyto-approaches and their achievements related to unreduced gamete formation has been authored by Ramanna and Jacobsen (2003).

Access to female gametophytes in order to carry out cytological observations is more difficult and time consuming. This explains that seed sets on the mother hybrid plant, either by selfing or after pollination with any of the parents, provides the only reliable evaluation of female fertility (e. g., Chevre et al., 1998).

The cytological basis of pollen sterility has been established in many interspecific hybrids by visualization of chromosome pairing and segregation during microsporogenesis, which is generally characterized by univalents and multivalents (e.g., Kerlan et al., 1993; Mariam et al., 1996) as well as many other meiotic abnormalities including lagging chromosomes or chromatids, chromatin bridges, asynchronous nuclei during the second division and micronuclei (e.g., Atlagic et al., 1993; Ulloa et al., 1994; Haroun, 1996; Soares-Scott et al., 2003). Multiple irregularities related to meiotic spindle behaviour have also been demonstrated by conventional chromatin staining (Shamina et al., 2005). It is very likely that such mechanisms also affect egg cell fertility.

The processes from pollination to fertilization are relevant within the crop-to-wild gene flow scheme since pollenstyle incompatibility and delayed or incomplete pollen tube growth have been demonstrated to be important as early post-zygotic barriers between species (e.g., Lefol et al., 1996; reviewed in Tiffin et al., 2001). Following pollination, pollen germination and tube growth can be observed, even in vivo, with fluorescence microscopy after differential staining of pollen cell walls and nuclei with aniline blue and DAPI, respectively (Williams et al., 1999; Feijo et al., 1999) (Fig. 13). Scanning electron microscopy can also be used to examine adherence, germination and growth of the pollen tube on the stigma from fixed tissues (Liu et al., 2004). The panel of hybrids in which these methodologies have been applied is limited but covers a wide range of taxa, from crops like rice (Liu et al., 2004) and pea (Ochatt et al., 2004) to trees like cork (Boavida et al., 2001) or birch (Williams et al., 1999), which indicates that they are potentially transferable to interspecific hybrids from any cultivated species. The complete set of recipes for pollen observations in Arabidopsis compiled by Johnson-Brousseau and McCormick (2004) could also be certainly worthy in studies on interspecific hybrids.

\section{Karyotype evolution in hybrid progenies}

Two purposes can be outlined for cytological analysis on crop $\times$ wild hybrid progenies: to determine the chromosome constitutions in the offspring from the interspecific hybrid or subsequent generations, and to characterize cropwild recombinant chromosomes eventually transmitted to their progenies.

Flow cytometry and karyotype analysis by means of traditional or DAPI staining methods are routine techniques to confirm the expected $2 \mathrm{n}$ value of individuals in selfed $\left(\mathrm{F}_{2}\right)$ or backcrossed $\left(\mathrm{BC}_{1}\right)$ hybrid progenies (Anderson et al., 1991; Inomata, 2002; Herrera et al., 2004; Chevre et al., 2007). But these approaches can lead to inconclusive results on the following early generations derived from the original hybrid, which are characterized by a high frequency of aneuploid complement transmission (Nassar et al., 1995; Atlagic and Skoric, 1999). In these situations, techniques that discriminate specific chromosomes or genomes are more helpful (Parokonny et al., 1997; Benavente et al., 2001; Peterka et al., 2002; Wang et al., 2002) and may be again a confident complement to approaches based on species-specific molecular markers (e.g., Ochatt et al., 2004). It can be added that cytological methods disclosing the chromosome or DNA content in hybrid progenies have served to demonstrate the formation of unreduced gametes (pollen or eggs or both) in many crop $\times$ wild hybrids (Anderson et al., 1991; Nassar et al., 1995; Lefol et al., 1996; Hussain et al., 1997; Chevre et al., 2007), as well as to evidence the straight relation between $2 \mathrm{n}$-gamete production and hybrid fertility (Wei et al., 2006).

The second main reason for cytogenetic studies on interspecific hybrid progenies is to monitor the transmission and stabilization of specific chromosomes or recombinants in the hybrid lineage. The usefulness of these techniques for unequivocal demonstration of alien introgression in many different crops is heavily documented (e.g., Friebe et al., 1996; Dilkova et al., 2000) while only a few studies deal with crop-to-wild genome transfer (Chevre et al., 2007). De novo meiotic formation of crop-wild recombinants in the subsequent generations can also be assessed either indirectly, as based upon the evidence of allosyndetic pairing in MI cells of hybrid descents (Anderson et al., 1991; Hussain et al., 1997; Lim et al., 2000; Ji and Chetelat, 2003), or by direct cytological demonstration of new recombinant chromosomes (Parokonny et al., 1997; Morgan et al., 2001).

Initial screening of hybrid progenies is generally based on approaches that check incorporation of specific traits (i.e., disease resistances) or molecular markers from the donor parent. Once genetic transfer has been demonstrated, then cytological analyses are conducted to confirm introgression and, in some instances, to further determine the amount and chromosome location of the alien chromatin on the hybrid derivatives (e.g., Friebe et al., 1996; Zhang et al., 2001; Wei et al., 2003; Kosmala et al., 2006). However, preliminary cytogenetic analyses can provide useful information on the potential for gene exchange at a wide genome level (Parokonny et al., 1997; Benavente et al., 2001) and may serve to identify the chromosomes for which interspecific transfer has the greatest probability of occurring.

$\mathrm{C}$-banding has been very efficient for physical mapping of alien segments in wheat breeding lines (e.g., Friebe et al., 1996) and other interspecific hybrid derivatives (Lukaszewski, 1995). However, the contribution of this technique for studies in other crops is virtually none. Despite some technical limitations demonstrated by Lukaszewski et al. (2005), GISH is currently the most common tool to visualize alien segments in crop genomes. The numerous examples cited in earlier reviews (Jiang and Gill, 1994; Gill and Friebe, 
1998; Humphreys et al., 2003; Gupta et al., 2005) mostly refer to species having large chromosomes. However, an increasing number of reports confirms that this method can also be successful in detecting stable introgression in crop species less suitable for cytogenetic analyses like rice (Yan et al., 2001; Jin et al., 2006), sugar beet (Desel et al., 2002), coffee (Herrera et al., 2007) (Fig. 9) and potato (Dong et al., 2001) (Fig. 10). Though mitotic chromosomes are the common target for ISH procedures, cytological demonstration of introgressions on meiotic pachytene spreads is also documented (Garriga-Caldere et al., 1999; Desel et al., 2002). GISH a nalyses are sometimes followed by molecular marker approaches for further identification of the specific alien chromosomes or chromosome segments incorporated into the recipient genome (Tang et al., 2005; Ma et al., 2006), but this goal can also be achieved by sequential or simultaneous FISH of total genomic DNAs with other classes of DNA probes (Dong et al., 2001; Kosmala et al., 2006; Herrera et al., 2007) (see Figs. 9, 10).

\section{Concluding remarks (a starting point?)}

This paper aimed to indicate some important steps that have to be addressed to evaluate the probability of unintentional gene transfer between crops and related species. It is clearly apparent from the literature that only a few cases have yet been documented and they mostly involve main crops on which a lot of work has been carried out. Thus, there is a need to investigate the gene transfer potential in an enlarged group of species, including those for which transgenesis is programmed. The number of species concerned is remarkably higher than the number of species for which genomic resources are available to carry out sequencing or molecular genotyping. In these cases, cytogenetic techniques are very valuable tools to get a quick and accurate diagnosis of the possibility of gene transfer and establishment of stable introgression. Some techniques may be poorly efficient for gene flow studies between close species with slightly divergent genomes. However, when the two partner species have differentiated genomes, cytogenetic methods can rapidly be used to identify the potential progenitors of a hybrid and the wild chromosome segments susceptible to preferentially receive the crop genetic sequences. Cytogenetics may also be used as a complement to phylogenetic studies based on gene sequencing when their results allege ancient gene flow between species. If the transferred segment has not been deeply modified in its repeated elements composition, cytogenetic tools can still reveal its alien origin. Such data are critically needed to elaborate a long term vision of the efficiency of gene transfer in species adaptation. As transgenesis is still in its childhood, documenting older events may help to discuss the fate of a transgene eventually disseminated in the wild.

\section{Acknowledgements}

We are very grateful to Dr. Tomas Naranjo for providing the image shown in Fig. 2, as well as to all other researchers that have sent original files of their published images.

\section{References}

Alexander MP: Differential staining of aborted and nonaborted pollen. Stain Technol 44:117-122 (1969).

Ali SNH, Ramanna MS, Jacobsen E, Visser RGF: Genome differentiation between Lycopersicon esculentum and $L$. pennellii as revealed by genomic in situ hybridization. Euphytica 127: 227-234 (2002).

Anderson JA, Taylor NL, Williams EG: Cytology and fertility of the interspecific hybrid Trifolium ambiguum $\times T$. repens and backcross populations. Crop Sci 31:683-687 (1991).

Arnold ML: Natural Hybridization and Evolution. (Oxford University Press, Oxford 1997).

Arnold ML, Bulger MR, Burke JM, Hempel AL, Williams JH: Natural hybridization: How low can you go and still be important? Ecology 80: 371-381 (1999).

Atlagic J, Skoric D: Cytogenetic study of Helianthus laevigatus and its $\mathrm{F} 1$ and BC1F1 hybrids with cultivated sunflower, Helianthus annuus. Plant Breeding 118:555-559 (1999).

Atlagic J, Dozet B, Skoric D: Meiosis and pollen viability in Helianthus tuberosus $\mathrm{L}$ and its hybrids with cultivated sunflower. Plant Breeding 111: 318-324 (1993).
Barba-Gonzalez R, Lim KB, Ramanna MS, Visser RGF, Van Tuyl JM: Occurrence of 2n gametes in the F1 hybrids of Oriental $\times$ Asiatic lilies ( $L i-$ lium): Relevance to intergenomic recombination and backcrossing. Euphytica 143:67-73 (2005).

Barcaccia G, Tavoletti S, Mariani A, Veronesi F: Occurrence, inheritance and use of reproductive mutants in alfalfa improvement. Euphytica 133 $37-56(2003)$

Benavente E, Fernandez-Calvin B, Orellana J: Relationship between the levels of wheat-rye metaphase I chromosomal pairing and recombinantion revealed by GISH. Chromosoma 105:9296 (1996).

Benavente E, Orellana J, Fernandez-Calvin B: Comparative analysis of the meiotic effects of wheat ph $1 b$ and $p h 2 b$ mutations in wheat $\times$ rye hybrids. Theor Appl Genet 96:1200-1204 (1998).

Benavente E, Alix K, Dusautoir JC, Orellana J, David JL: Early evolution of the chromosomal structure of Triticum turgidum - Aegilops ovata amphiploids carrying and lacking the $P h 1$ gene. Theor Appl Genet 103:1123-1128 (2001).

Binsfeld PC, Wingender R, Schnabl H: Cytogenetic analysis of interspecific sunflower hybrids and molecular evaluation of their progeny. Theor Appl Genet 102:1280-1285 (2001).
Boavida LC, Silva JP, Feijo IA: Sexual reproduction in the cork oak ( $Q$ uercus suber L). - II. Crossing intra- and interspecific barriers. Sex Plant Reprod 14:143-152 (2001).

Bretagnolle F, Thompson JD: Tansley Review No. 78. Gametes with the somatic chromosome number. Mechanisms of their formation and role in the evolution of autopolyploid plants. New Phytol 129:1-22 (1995).

Burke JM, Tang S, Knapp SI, Rieseberg LH: Genetic analysis of sunflower domestication. Genetics 161:1257-1267 (2002).

Chen JF, Staub J, Tashiro Y, Isshiki S, Miyazaki S Successful interspecific hybridization between Cucumis sativus L. and C. hystrix Chakr. Euphytica 96:413-419 (1997).

Chen J, Staub J, Qian C, Jiang J, Luo X, Zhuang F: Reproduction and cy togenetic characterization of interspecific hybrids derived from Cucumis hystrix Chakr. $\times$ Cucumis sativus L. Theor Appl Genet 106:688-695 (2003).

Chevre AM, Eber F, Baranger A, Hureau G, Barret $P$, et al: Characterization of backcross generations obtained under field conditions from oilseed rape wild radish F1 interspecific hybrids: an assessment of transgene dispersal. Theor Appl Genet 97:90-98 (1998). 
Chevre AM, Eber F, Jenczewski E, Darmency H, Renard M: Gene flow from oilseed rape to weedy species. Acta Agr Scand B-S P53:22-25 (2003).

Chevre AM, Adamczyk K, Eber F, Huteau V, Coriton $\mathrm{O}$, et al: Modelling gene flow between oilseed rape and wild radish. I. Evolution of chromosome structure. Theor Appl Genet 114: 209-221 (2007)

Choudhary BR, Joshi P, Ramarao S: Interspecific hybridization between Brassica carinata and Brassica rapa. Plant Breeding 119:417-420 (2000).

Choudhary BR, Joshi P, Rao SR: Cytogenetics of Brassica juncea $\times$ Brassica rapa hybrids and patterns of variation in the hybrid derivatives. Plant Breeding 121:292-296 (2002).

Chung CS, Yoshida KT, Takeda G: Reproductive characteristics of amphidiploids derived from an interspecific hybrid between Nicotiana trigonophylla Dun and $N$. tabacum L. Breeding Sci 46:29-33 (1996).

Cifuentes M, Blein M, Benavente E: A cy tomolecular approach to assess the potential of gene transfer from a crop (Triticum turgidum L.) to a wild relative (Aegilops geniculata Roth.). Theor Appl Genet 112:657-664 (2006).

Conicella C, Capo A, Cammareri M, Errico A, Shamina N, Monti LM: Elucidation of meiotic nuclear restitution mechanisms in potato through analysis of microtubular cy toskeleton. Euphytica 133:107-115 (2003).

Cuadrado A, Vitellozzi F, Jouve N, Ceoloni C: Fluorescence in situ hybridization with multiple repeated DNA probes applied to the analysis of wheat-rye chromosome pairing. Theor Appl Genet 94:347-355 (1997).

Cuñado N, Cermeño MC, Orellana J: Interactions between wheat, rye and Aegilops ventricosa chromosomes on homologous and homoeologous pairing. Heredity 56:219-226 (1986).

Desel C, Jansen R, Gue DD, Schmidt T: Painting of parental chromatin in Beta hybrids by multicolour fluorescent in situ hybridization. Ann Bot London 89:171-181 (2002).

Dhaliwal HS, Gill BS, Waines JG: Analysis of induced homoeologous pairing in a $p h$ mutant wheat $\times$ rye hybrid. J Hered 68:206-209 (1977).

Dilkova M, Jellen EN, Forsberg RA: C-banded karyotypes and meiotic abnormalities in germplasm derived from interploidy crosses in Avena. Euphytica 111:175-184 (2000).

Dolezel J, Lucretti S, Schubert I: Plant chromosome analysis and sorting by flow cytometry. Crit Rev Plant Sci 13:275-309 (1994).

Dong FG, McGrath JM, Helgeson JP, Jiang JM: The genetic identity of alien chromosomes in potato breeding lines revealed by sequential GISH and FISH analyses using chromosome-specific cytogenetic DNA markers. Genome 44:729-734 (2001).

Eber F, Tanguy X, Chevre AM, Baranger A, Vallee $\mathrm{P}$, Renard M: Spontaneous hybridization between a male-sterile oilseed rape and 2 weeds Theor Appl Genet 88:362-368 (1994).

Eeckhaut T, Leus L, Van Huylenbroeck J: Exploitation of flow cy tometry for plant breeding. Acta Physiol Plant 27:743-750 (2005).

Ellstrand NC: Current knowledge of gene flow in plants: implications for transgene flow. Phil Trans R Soc B 358:1163-1170 (2003).

Ellstrand NC, Whitkus R, Rieseberg LH: Distribution of spontaneous plant hybrids. Proc Natl Acad Sci USA 93:5090-5093 (1996).

Ellstrand NC, Prentice HC, Hancock JF: Gene flow and introgression from domesticated plants into their wild relatives. Annu Rev Ecol Syst 30: 539-563 (1999).
Ewald A, Lepper L, Lippold R, Schwenkel HG: Sexual reproduction of interspecific hybrids between Cyclamen persicum MILL. and Cyclamen purpurascens MILL. Gartenbauwissenschaft 65:162-169 (2000).

Feijo J, CertalA, Boavida L, Van Nerum I, Valdiviesso $T$, et al: Advances on the study of sexual reproduction in the cork-tree (Quercus suber L.), chestnut (Castanea sativa Mill.) and in Rosaceae (apple and almond), in Cresti M, Cai G, Moscatelli M (eds): Fertilisation in Higher Plants: Molecular and Cytological Aspects, pp 377-394 (Springer-Verlag, Berlin 1999).

Fernandez-Calvin B, Orellana J: Relationship between pairing frequencies and genome affinity estimations in Aegilops ovata $\times$ Triticum aestivum hybrid plants. Heredity 68:165-172 (1992).

Fernandez-Calvin B, Benavente E, Orellana J: Meiotic pairing in wheat-rye derivatives detected by genomic in-situ hybridization and C-banding - a comparative analysis. Chromosoma 103: 554-558 (1995).

Fransz $\mathrm{P}$, Armstrong $\mathrm{S}$, Alonso-Blanco C, Fischer TC, Torres-Ruiz RA, Jones G: Cytogenetics for the model system A rabidopsis thaliana. Plant J 13:867-876 (1998).

Friebe B, Jiang J, Raupp WJ, Mcintosh RA, Gill BS: Characterization of wheat-alien translocations conferring resistance to diseases and pests: Current status. Euphytica 91:59-87 (1996).

Garriga-Caldere K, Huigen DJ, Jacobsen E, Ramanna MS: Prospects for introgressing tomato chromosomes into the potato genome: An assessment through GISH analysis. Genome 42 : 282-288 (1999).

Gatt M, Hammett K, Murray B: Interspecific hybridization and the analysis of meiotic chromosome pairing in Dahlia (Asteraceae-Heliantheae) species with $\mathrm{x}=6$. Plant Syst Evol 221:25-33 (2000).

Genualdo G, Errico A, Tiezzi A, Conicella C: alphaTubulin and $\mathrm{F}$-actin distribution during microsporogenesis in a $2 \mathrm{n}$ pollen producer of Solanum. Genome 41:636-641 (1998).

Gill BS, Friebe B: Plant cy togenetics at the dawn of the 21st century. Curr Opin Plant Biol 1:109115 (1998).

Gill BS, Friebe B, Endo TR: Standard karyotype and nomenclature system for description of chromosome bands and structural aberrations in wheat (Triticum aestivum). Genome 34:830839 (1991).

Gonzalez G, Comas C, Confalonieri V, Naranjo CA Poggio L: Genomic affinities between maize and Zea perennis using classical and molecular cytogenetic methods (GISH-FISH). Chromosome Res 14:629-635 (2006).

Gupta PK, Kulwal PL, Rustgi S: Wheat cy togenetics in the genomics era and its relevance to breeding. Cytogenet Genome Res 109:315-327 (2005).

Haroun SA: Chromosome association and pollen fertility of parental and interspecific hybrids of Lycopersicon esculentum $\times L$. hirsutum and $L$. pennellii. Genetica 98:103-106 (1996).

Herrera JC, Combes MC, Cortina H, Lashermes P. Factors influencing gene introgression into the allotetraploid Coffea arabica L. from its diploid relatives. Genome 47:1053-1060 (2004).

Herrera J, D'Hont A, Lashermes P: Use of fluorescence in situ hybridization as a tool for introgression analysis and chromosome identification in coffee (Coffea arabica L.). Genome 50: $619-626(2007)$
Heslop-Harrison J, Heslop-Harrison Y: Evaluation of pollen viability by enzymatically induced fluorescence. Intracellular hydrolysis of fluorescein diacetate. Stain Technol 45:115-120 (1970).

Humphreys MW, Canter PJ, Thomas HM: Advances in introgression technologies for precision breeding within the Lolium - Festuca complex. Ann Appl Biol 143:1-10 (2003).

Hussain SW, Williams WM, Woodfield DR, Hampton JG: Development of a ploidy series from a single interspecific Trifolium repens L. $\times$ T. nigrescens Viv F1 hybrid. Theor Appl Genet 94: 821-831 (1997)

Hutchinson J, Miller TE, Reader SM: C-banding at meiosis as a means of assessing chromosome affinities in the Triticeae. Can J Genet Cytol 25 319-323 (1983)

Inomata $\mathrm{N}$ : A cytogenetic study of the progenies of hybrids between Brassica napus and Brassica oleracea, Brassica bourgeaui, Brassica cretica and Brassica montana. Plant Breeding 121:174$176(2002)$.

Irigoyen ML, Linares C, Ferrer E, Fominaya A: Fluorescence in situ hybridization mapping of Avena sativa L. cv. SunII and its monosomic lines using cloned repetitive DNA sequences. Genome 45:1230-1237 (2002).

Ishizaka H: Chromosome association and fertility in the hybrid of Cyclamen persicum Mill and C. hederifolium Aiton and its amphidiploid. Breeding Sci 44:367-371 (1994).

Jauhar PP, Dogramaci M, Peterson TS: Synthesis and cytological characterization of trigeneric hybrids of durum wheat with and without $P h I$. Genome 47:1173-1181 (2004).

Ji Y, Chetelat RT: Homoeologous pairing and recombination in Solanum lycopersicoides monosomic addition and substitution lines of tomato. Theor Appl Genet 106:979-989 (2003).

Jiang JM, Gill BS: Nonisotopic in situ hybridization and plant genome mapping: The first 10 years. Genome 37:717-725 (1994).

Jiang JM, Gill BS: Current status and the future of fluorescence in situ hybridization (FISH) in plant genome research. Genome 49:1057-1068 (2006).

Jin HH, Tan GX, Brar DS, Tang M, Li G, et al: Molecular and cytogenetic characterization of an Oryza officinalis-O. sativa chromosome 4 addition line and its progenies. Plant Mol Biol 62: 769-777 (2006)

Johnson-Brousseau SA, McCormick S: A compendium of methods useful for characterizing $A r a$ bidopsis pollen mutants and gametophyticallyexpressed genes. Plant J 39:761-775 (2004).

Jouve N, Giorgi B: Analysis of induced homoeologous pairing in hybrids between $6 \mathrm{x}$ Triticale Ph1 mutant and Triticum aestivum L. Can J Genet Cytol 28:696-700 (1986).

Karlov GI, Khrustaleva LI, Lim KB, Van Tuyl JM: Homoeologous recombination in $2 n$-gametes producing interspecific hybrids of Lilium (Liliaceae) studied by genomic in situ hybridization (GISH). Genome 42:681-686 (1999).

Kerlan MC, Chevre AM, Eber F: Interspecific hybrids between a transgenic rapeseed (Brassica napus) and related species - Cytogenetical characterization and detection of the transgene. Genome 36:1099-1106 (1993).

King IP, Purdie KA, Orford SE, Reader SM, Miller TE: Detection of homoeologous chiasma formation in Triticum durum $\times$ Thinopyrum bessarabicum hybrids using genome in situ hybridization. Heredity 71:369-372 (1993) 
King IP, Reader SM, Purdie KA, Orford SE, Miller TE: A study of the effect of a homoeologous pairing promoter on chromosome pairing in wheat/rye hybrids using genomic in situ hybridization. Heredity 72:318-321 (1994).

Kosmala A, Zwierzykowski Z, Gasior D, Rapacz M, Zwierzykowska E, Humphreys MW: GISH/ FISH mapping of genes for freezing tolerance transferred from Festuca pratensis to Lolium multiflorum. Heredity 96:243-251 (2006).

Lam E, Kato N, Watanabe K: Visualizing chromosome structure/organization. Annu Rev Plant Biol 55:537-554 (2004).

Lan WZ, Qin R, Li G, He GC: Comparative analysis of $\mathrm{A}, \mathrm{B}, \mathrm{C}$ and $\mathrm{D}$ genomes in the genus Oryza with Cot-1 DNA of C genome. Chin Sci Bull 51: 1710-1720 (2006).

Leflon M, Eber F, Letanneur JC, Chelysheva L, Coriton $\mathrm{O}$, et al: Pairing and recombination at meiosis of Brassica rapa (AA) $\times$ Brassica napus (AACC) hybrids. Theor Appl Genet 113:14671480 (2006)

Lefol E, Fleury A, Darmency H: Gene dispersal from transgenic crops. 2. Hybridization be tween oilseed rape and the wild heavy mustard. Sex Plant Reprod 9:189-196 (1996).

Lim KB, Chung JD, Van Kronenburg BCE, Ramanna MS, De Jong JH, Van Tuyl JM: Introgression of Lilium rubellum Baker chromosomes into $L$. longiflorum Thunb.: A genome painting study of the $\mathrm{F} 1$ hybrid, $\mathrm{BC} 1$ and $\mathrm{BC} 2$ progenies. Chromosome Res 8:119-125 (2000).

Lim KB, Ramanna MS, De Jong JH, Jacobsen E, Van Tuyl JM: Indeterminate Meiotic Restitution (IMR): a novel type of meiotic nuclear restitution mechanism detected in interspecific lily hybrids by GISH. Theor Appl Genet 103:219230 (2001).

Lim KB, Shen TM, Barba-Gonzalez R, Ramanna MS, Van Tuyl JM: Occurrence of SDR 2N-gametes in Lilium hybrids. Breeding Sci 54:13-18 (2004).

Liu HY, Xu CG, Zhang QF: Male and female gamete abortions, and reduced affinity between the uniting gametes as the causes for sterility in an indica/japonica hybrid in rice. Sex Plant Reprod 17:55-62 (2004).

Lu BR, Snow AA: Gene flow from genetically modified rice and its environmental consequences. Bioscience 55:669-678 (2005).

Lukaszewski AJ: Physical distribution of translocation breakpoints in homoeologous recombinants induced by the absence of the $P h I$ gene in wheat and triticale. Theor Appl Genet 90:714719 (1995).

Lukaszewski AJ, Lapinski B, Rybka K: Limitations of in situ hybridization with total genomic DNA in routine screening for alien introgressions in wheat. Cytogenet Genome Res 109: 373-377 (2005)

Ma N, Li ZY, Cartagena IA, Fukui K: GISH and AFLP analyses of novel Brassica napus lines derived from one hybrid between B. napus and Orychophragmus violaceus. Plant Cell Rep 25: 1089-1093 (2006)

Maestra B, Naranjo T: Homoeologous relationships of Triticum sharonense chromosomes to T. aes tivum. Theor Appl Genet 94:657-663 (1997).

Maluszynska J, Hasterok R: Identification of individual chromosomes and parental genomes in Brassica juncea using GISH and FISH. Cytogenet Genome Res 109:310-314 (2005).

Marasek A, Mizuochi H, Okazaki K: The origin of Darwin hybrid tulips analyzed by flow cytometry, karyotype analyses and genomic in situ hybridization. Euphytica 151:279-290 (2006).

Marhold K, Lihova J: Polyploidy, hybridization and reticulate evolution: lessons from the Brassicaceae. Plant Syst Evol 259:143-174 (2006).
Mariam AL Zakri AH, Mahani MC, Normah MN Interspecific hybridization of cultivated rice, Oryza sativa $\mathrm{L}$ with the wild rice, $O$. minute Presl. Theor Appl Genet 93:664-671 (1996).

Matsuoka Y, Takumi S, Kawahara T: Natural variation for fertile triploid F1 hybrid formation in allohexaploid wheat speciation. Theor Appl Genet 115:509-518 (2007).

Mok DWS, Peloquin SJ: Three mechanisms of $2 n$ pollen formation in diploid potatoes. Can Genet Cy tol 17:217-225 (1975).

Morgan WG, King IP, Koch S, Harper JA, Thomas HM: Introgression of chromosomes of Festuce arundinacea var. glaucescens into Lolium multiflorum revealed by genomic in situ hybridisation (GISH). Theor Appl Genet 103:696-701 (2001).

Naranjo T, Maestra B: The effect of $p h$ mutations on homoeolgous pairing in hybrids of wheat with Triticum longissimum. Theor Appl Genet 91: $1265-1270$ (1995).

Naranjo $T$, Roca A, Goicoechea $P G$, Giraldez $R$. Arm homoeology of wheat and rye chromosomes. Genome 29:873-882 (1987).

Nassar NMA, Freitas M: Prospects of polyploidizing cassava, Manihot esculenta Crantz, by unreduced microspores. Plant Breeding 116:195197 (1997).

Nassar HN, Nassar NMA, Vieira C, Saraiva LS: Cytogenetic behavior of the interspecific hybrid of Manihot neusana Nassar and cassava, $M$. esculenta Crantz, and its backcross progeny. Can J Plant Sci 75:675-678 (1995).

Ochatt SJ, Benabdelmouna A, Marget P, Aubert G, Moussy F, et al: Overcoming hybridization barriers between pea and some of its wild relatives. Euphytica 137:353-359 (2004).

Orellana J: Most of the homoeologous pairing at metaphase I in wheat-rye hybrids is not chiasmatic. Genetics 111:917-931 (1985).

Parokonny AS, Marshall JA, Bennett MD, Cocking EC, Davey MR, Power JB: Homoeologous pairing and recombination in backcross derivatives of tomato somatic hybrids (Lycopersicon esculentum(+) L. peruvianum). Theor Appl Genet 94:713-723 (1997).

Peterka H, Budahn H, Schrader O, Havey MJ Transfer of a male-sterility-inducing cytoplasm from onion to leek (Allium ampeloprasum). Theor Appl Genet 105:173-181 (2002).

Pickering RA, Hudakova S, Houben A, Johnston PA, Butler RC: Reduced metaphase I associations between the short arms of homoeologous chromosomes in a Hordeum vulgare L. $\times H$. bulbosum L. diploid hybrid influences the frequency of recombinant progeny. Theor Appl Genet 109:911-916 (2004).

Piperidis G, Christopher MJ, Carroll BJ, Berding N, D'Hont A: Molecular contribution to selection of intergeneric hybrids between sugarcane and the wild species Erianthus arundinaceus. Genome 43:1033-1037 (2000).

Qu LP, Vorsa N: Desynapsis and spindle abnormalities leading to 2 n pollen formation in Vaccini um darrowi. Genome 42:35-40 (1999).

Ramanna MS, Jacobsen E: Relevance of sexual polyploidization for crop improvement - A review. Euphytica 133:3-18 (2003).

Ramanna MS, Kuipers AGJ, Jacobsen E: Occurrence of numerically unreduced (2n) gametes in Alstroemeria interspecific hybrids and their significance for sexual polyploidisation. Euphytica 133:95-106 (2003).

Rao NB, Valli TS, Lakshmi N: Cy togenetic studies on the interspecific hybrid Capsicum baccatum $\mathrm{L} \times$ C. frutescens $\mathrm{L}$ and its progeny. Euphytica 59:135-140 (1992).
Reddy LJ, Rao NK, Saxena KB: Production and characterization of hybrids between Cajanus cajan $\times$ C. reticulatus var. grandifolius. Euphytica 121:93-98 (2001).

Reichman JR, Watrud LS, Lee EH, Burdick CA Bollman MA, et al: Establishment of transgenic herbicide-resistantcreeping bentgrass (Agrosti stolonifera L.) in nonagronomic habitats. Mol Ecol 15:4243-4255 (2006).

Rieseberg LH: Hybrid origins of plant species. Annu Rev Ecol Syst 28:359-389 (1997).

Rieseberg LH, Burke JM: The biological reality of species: gene flow, selection, and collective evolution. Taxon 50:47-67 (2001).

Rieseberg LH, Carney SE: Plant hybridization. New Phytol 140:599-624 (1998).

Rieseberg LH, Ellstrand NC: What can molecular and morphological markers tell us about plant hybridization. Crit Rev Plant Sci 12:213-241 (1993).

Rieseberg LH, Wendel J: Plant speciation - rise of the poor cousins. New Phytol 161:3-8 (2004).

Rodriguez S, Maestra B, Perera E, Diez M, Naranjo $\mathrm{T}$ : Pairing affinities of the $\mathrm{B}$ - and $\mathrm{G}$-genome chromosomes of polyploid wheats with those of Aegilops speltoides. Genome 43:814-819 (2000).

Schwarzacher T, Anamthawat-Jonsson K, Harrison GE, Islam A, Jia JZ, et al: Genomic in situ hybridization to identify alien chromosomes and chromosome segments in wheat. Theor Appl Genet 84:778-786 (1992)

Shamina NV: A catalogue of abnormalities in the division spindles of higher plants. Cell Biol Int 29:384-391 (2005).

Soares-Scott MD, Meletti LM, Recco-Pimentel SM Meiotic behaviour and pollen fertility in sexua and somatic hybrids of Passiflora species. Caryologia 56:129-137 (2003).

Stebbins GL: On the hybrid origin of the Angiosperms. Evolution 12:267-270 (1958)

Stefani A: Unreduced gametes in the F1 hybrid of Triticum durum Desf $\times$ Haynaldia villosa Schur. Z Pflanzenzucht 96:8-14 (1986).

Stevenson M, Armstrong SJ, Ford-Lloyd BV, Jones GH: Comparative analysis of crossover exchanges and chiasmata in Allium cepa $\times$ fistulosum after genomic in situ hybridization (GISH). Chromosome Res 6:567-574 (1998).

Tang QL, Rong TZ, Song YC, Yang JP, Pan GT, et al Introgression of perennial teosinte genome into maize and identification of genomic in situ hybridization and microsatellite markers. Crop Sci 45:717-721 (2005).

Techio VH, Davide LC, Pereira AV: Meiosis in elephant grass (Pennisetum purpureum), pear millet (Pennisetum glaucum) (Poaceae, Poales) and their interspecific hybrids. Genet Mol Biol 29:353-362 (2006)

Tiffin P, Olson MS, Moyle LC: Asymmetrical crossing barriers in angiosperms. Proc R Soc Lond $\mathrm{B}$ Biol 268:861-867 (2001).

Ulloa M, Corgan N, Dunford M: Chromosome characteristics and behavior differences in $\mathrm{Al}$ lium fistulosum L, Allium cepa L, their F1 hybrid, and selected backcross progeny. Theor Appl Genet 89:567-571 (1994).

Van Tuyl JM, De Vries JN, Bino RJ, Kwakkenbos TAM: Identification of $2 n$-pollen producing interspecific hybrids of Lilium using flow-cy tometry. Cytologia 54:737-745 (1989).

Vriesendorp B, Bakker FT: Reconstructing patterns of reticulate evolution in angiosperms: what can we do? Taxon 54:593-604 (2005)

Wang K, Guo WZ, Zhang TZ: Detection and mapping of homologous and homoeologous segments in homoeologous groups of allotetraploid cotton by BAC-FISH. Theor Appl Genet 8:675-682 (2007) 
Wang YP, Snowdon RJ, Rudloff E, Wehling P, Friedt W, Sonntag K: Cytogenetic characterization and fael gene variation in progenies from asymmetric somatic hybrids between Brassica napus and Crambe abyssinica. Genome 47:724731 (2004).

Wang ZN, Zemetra RS, Hansen J, Hang A, MallorySmith CA, Burton C: Determination of the paternity of wheat (Triticum aestivum $\mathrm{L}$ ) $\times$ jointed goatgrass (Aegilops cylindrica Host) BC1 plants by using genomic in situ hybridization (GISH) technique. Crop Sci 42:939-943 (2002).

Warwick SI, Simard MJ, Legere A, Beckie HJ, Braun $\mathrm{L}$, etal: Hybridization between transgenic Brassica napus L. and its wild relatives: Brassica rapa L., Raphanus raphanistrum L., Sinapis arvensis L., and Erucastrum gallicum (Willd.) OE Schulz. Theor Appl Genet 107:528-539 (2003).

Watrud LS, Lee EH, Fairbrother A, Burdick C, Reichman JR, et al: Evidence for landscape-level, pollen-mediated gene flow from genetically modified creeping bentgrass with CP4 EPSPS as a marker. Proc Natl Acad Sci USA 101:1453314538 (2004).
Wei WH, Zhao WP, Song YC, Liu LH, Guo LQ, Gu MG: Genomic in situ hybridization analysis for identification of introgressed segments in alloplasmic lines from Zea mays $\times$ Zea diploperen nis. Hereditas 138:21-26(2003)

Wei WH, Zhang SF, Li J, Wang LJ, Chen B, et al Analysis of $\mathrm{F} 1$ hybrid and $\mathrm{BCl}$ monosomic alien addition line plants from Brassica oleracea $\times$ Sinapis alba by GISH. Chinese Sci Bull 51:2872-2877 (2006).

Williams JH, Friedman WE, Arnold ML: Developmental selection within the angiosperm style: Using gamete DNA to visualize interspecific pollen competition. Proc Natl Acad Sci USA 96: 9201-9206 (1999).

Xiong ZY, Tan GX, He GY, He GC, Song YC: Cytogenetic comparisons between $\mathrm{A}$ and $\mathrm{G}$ genomes in Oryza using genomic in situ hybridization. Cell Res 16:260-266 (2006)

$\mathrm{Xu} \mathrm{X,} \mathrm{Lu} \mathrm{J:} \mathrm{Cytogenetic} \mathrm{study} \mathrm{of} \mathrm{interspecific} \mathrm{hy-}$ brids between Vitis rotundifolia and Vitis vinifera. Acta Hort (ISHS) 640:269-273 (2004).
Yan $\mathrm{HH}$, Liu GQ, Cheng ZK, Min SK, Zhu LH: Characterization of euploid backcross progenies derived from interspecific hybrids between Oryza sativa and $O$. eichingeri by restriction fragment length polymorphism (RFLP) analysis and genomic in situ hybridization (GISH). Genome 44:86-95 (2001).

Zhang LT, Pickering R, Murray B: Direct measurement of recombination frequency in interspecific hybrids between Hordeum vulgare and $H$ bulbosum using genomic in situ hybridization. Heredity 83:304-309 (1999).

Zhang LT, Pickering RA, Murray BG: Hordeum vulgare $\times H$. bulbosum tetraploid hybrid provides useful agronomic introgression lines for breeders. N Z J Crop Hort 29:239-246 (2001).

Zhang P, Li WL, Friebe B, Gill BS: Simultaneous painting of three genomes in hexaploid wheat by BAC-FISH. Genome 47:979-987 (2004)

Zhang XZ, Liu GJ, Zhang DM: Occurrence and cytogenetic development of unreduced pollen in Vitis. Vitis 37:63-65 (1998). 